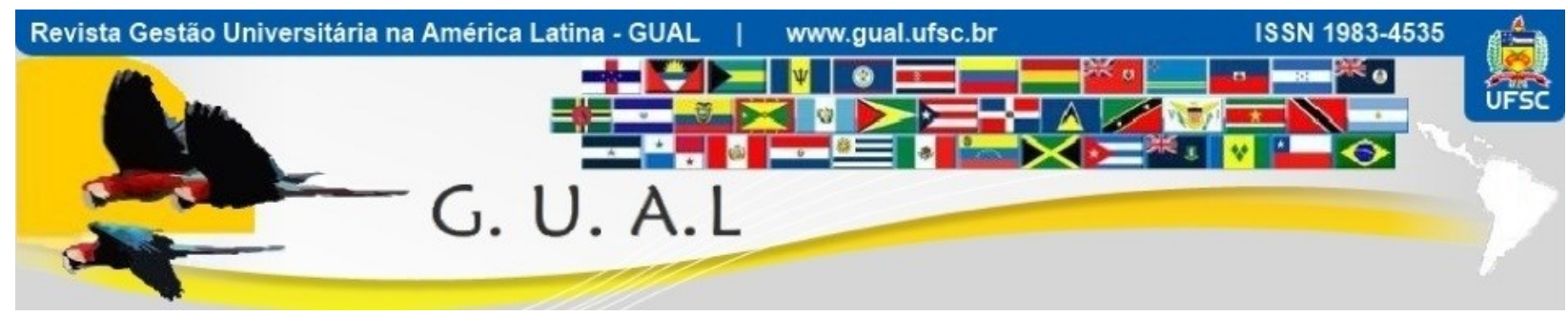

DOI: http://dx.doi.org/10.5007/1983-4535.2016v9n2p216

\title{
ATRIBUTOS DE PERMANÊNCIA DE ALUNOS EM INSTITUIÇÃO PÚBLICA DE ENSINO SUPERIOR
}

\section{STUDENTS PERMANENCE ATTRIBUTES IN PUBLIC INSTITUTION OF HIGHER EDUCATION}

\author{
Jucelia Appio, Doutora \\ Universidade Estadual do Oeste do Paraná - UNIOESTE \\ juceliaappio@yahoo.com.br \\ André Ricardo Pereira, Mestrando \\ Universidade Estadual do Oeste do Paraná - UNIOESTE \\ andre rpereira@yahoo.com.br \\ Déborah Luiza Marcon, Mestranda \\ Universidade Estadual do Oeste do Paraná - UNIOESTE \\ debomarcon_hotmail.com \\ Nelson Natalino Frizon, Mestre \\ União de Ensino do Sudoeste do Paraná - UNISEP \\ nfrizon@gmail.com
}

Recebido em 04/março/2014

Aprovado em 28/março/2016

Sistema de Avaliação: Double Blind Review

Esta obra está sob uma Licença Creative Commons Atribuição-Uso. 


\title{
RESUMO
}

O ensino superior no Brasil tem experimentado um relevante crescimento nos últimos anos, ao passo que as questões de permanência, retenção e evasão de alunos têm exigido crescentes esforços dos gestores das Instituições de Ensino Superior (IES) para garantir que o aluno ingresse, receba a formação e ao final o diploma. Este trabalho teve como objetivo identificar atributos de permanência de alunos em uma instituição pública de ensino superior do Paraná. Para tal, foi realizada uma pesquisa com 228 alunos matriculados no primeiro semestre de 2014. A pesquisa foi descritiva com abordagem quantitativa. O instrumento de coleta dos dados foi um questionário estruturado dividido em duas partes, na primeira, questões fechadas com uma escala de sete pontos do tipo Likert, na segunda, variáveis quantitativas e qualitativas para a descrição do perfil da amostra. A análise de regressão indicou que Confiança do aluno na instituição, Situação financeira do aluno e Atendimento às expectativas, foram os explicadores diretos da Permanência. Estes construtos explicaram $11,3 \%$ da variabilidade total da tendência à permanência. Considerações finais, limitações da pesquisa e sugestões para investigações futuras fazem parte da etapa final do trabalho.

Palavras-chave: Ensino superior. Instituição pública. Permanência.

\begin{abstract}
Higher education in Brazil has experienced significant growth in recent years, while the permanence, retention and students dropout are issues that have required increased efforts of managers of Higher Education Institutions to ensure that the student will join the institution, receive training and in end the diploma. This study aimed to identify students permanence attributes in a public institution of higher education of Paraná. To do this, a survey of 228 students enrolled in the first half of 2014 was conducted. The research was descriptive with quantitative approach. The data collection instrument was a structured questionnaire divided into two parts, the first, closed questions with a seven-point scale Likert, the second, quantitative and qualitative variables to describe the sample profile. Regression analysis indicated that student confidence in the institution, the financial situation of the student and how the institution met their expectations, were the direct exponents of permanence. These constructs explained $11.3 \%$ of the total variability of the permanence trend. Final considerations, research limitations and suggestions for future research are part of the final stage of work.
\end{abstract}

Keywords: Higher education. Public institution. Permanence. 


\section{INTRODUÇÃO}

O setor de serviços tem tido um grande impacto na economia, tanto no Brasil quanto na economia global, segundo Corrêa e Caon (2006, p. 23), “O principal indicador utilizado para evidenciar esse fato tem sido a participação do setor de serviços na ocupação de mão de obra e na geração de riqueza, refletida pelo Produto Interno Bruto”. O setor é responsável por mais de $60 \%$ da economia brasileira, com crescimento superior ao da economia total (Produto Interno Bruto - PIB), segundo dados do Instituto Brasileiro de Geografia e Estatística (IBGE), o setor de serviços variou nos anos de 2012 e 2013, 10\% e 8,5\% respectivamente.

No que concerne às instituições de ensino superior (IES), essas executam serviços onde os alunos são os receptores do serviço prestado, segundo Fitzsimmons e Fitzsimmons (2005), são serviços em massa e que se caracterizam pela ausência de customização, sendo oferecidos de uma única maneira para um grupo de clientes. A educação superior tem um importante papel no desenvolvimento da sociedade, como consta no Plano Nacional da Educação (PNE) "a produção de conhecimento [...] é a base do desenvolvimento científico e tecnológico e que este é que está criando o dinamismo das sociedades atuais" (BRASIL, 2000, p. 41). Ainda segundo o PNE, "nessas instituições apropria-se o patrimônio do saber humano que deve ser aplicado ao conhecimento e desenvolvimento do País e da sociedade brasileira" (BRASIL, 2000, p. 42).

O PNE trouxe como diretriz a expansão da oferta de ensino superior no Brasil para oportunizar aos egressos do ensino médio, o ingresso aos cursos de graduação. Para as IES públicas indicou "que o setor público neste processo, tenha uma expansão de vagas tal que, no mínimo, mantenha uma proporção nunca inferior a 40\% do total” (BRASIL, 2000, p. 42). Nesse contexto, surge o Programa de Apoio a Planos de Reestruturação e Expansão das Universidades Federais (REUNI), criado em 2007 através do Decreto $n^{\circ} 6.096$ e implantado no ano de 2008. Em sua formulação, o REUNI teve como principais objetivos: garantir as universidades as condições necessárias para a ampliação do acesso e permanência na educação superior; assegurar a qualidade por meio de inovações acadêmicas; promover a articulação entre os diferentes níveis de ensino, integrando a graduação, a pós-graduação, a educação básica e a educação profissional e tecnológica; e otimizar o aproveitamento dos recursos humanos e da infraestrutura das instituições federais de educação superior. (BRASIL, 2009). 
Além disso, o Governo Federal tem promovido ações de apoio a permanência e combate à evasão de alunos em IES Públicas, onde podemos destacar o Programa Nacional de Assistência Estudantil (PNAES), e o bolsa-permanência, que são ações de auxílio financeiro para estudantes de baixa renda das instituições federais de ensino superior. Não basta ampliar o acesso ao ensino superior, é preciso garantir a permanência dos alunos no curso de graduação.

O ensino superior no Brasil tem passado por diversas mudanças nas últimas décadas, a oferta de vagas, ainda que aquém da necessidade, tem se mantido crescente, enquanto que, observada a realidade das instituições de ensino superior no Brasil, quando se analisa o número de ingressantes e concluintes nos cursos de graduação oferecidos por essas instituições, a permanência dos alunos nos cursos escolhidos, indica tratar-se de um problema generalizado, observado tanto em IES públicas como em IES privadas.

O tema, permanência e evasão, possui tamanha importância para as IES públicas que levou o MEC, através da Secretaria de Educação Profissional e Tecnológica (SETEC), a instituir, em Novembro de 2013, um Grupo de Trabalho composto por membros da SETEC, do Conselho Nacional das Instituições da Rede Federal de Educação Profissional, Científica e Tecnológica e do Conselho dos Diretores das Escolas Técnicas das Universidades Federais, com as atribuições de elaborar um relatório sobre os índices de evasão e retenção na rede federal de educação profisssional, científica e tecnológica e elaborar um manual de orientação para o combate à evasão.

Dessa forma, essa pesquisa justificou-se por buscar identificar os principais atributos que contribuem na permanência de alunos em uma IES pública, e subsidiar ações de combate à evasão desses alunos. Apresentada a relevância desta temática este estudo teve como problema de pesquisa: Quais são os atributos de permanência de alunos em uma instituição pública de ensino superior? Buscando responder ao problema de pesquisa, o presente estudo teve como objetivo investigar os atributos de permanência de alunos de uma IES pública de Ensino Superior. E objetivos específicos: (a) Caracterizar os alunos pesquisados; (b) descrever os atributos de permanência destes alunos; (c) identificar quais atributos influenciam na permanência de alunos no ensino superior. Para tal propôs-se realizar uma pesquisa com abordagem quantitativa.

Este trabalho está estruturado da seguinte forma: Introdução, onde são apresentados o tema, o problema de pesquisa, o objetivo geral e a justificativa da pesquisa. Em seguida a revisão bibliográfica, metodologia, análise dos resultados e conclusão. 


\section{ENSINO SUPERIOR NO BRASIL}

Nas últimas décadas a educação superior no Brasil tem experimentado uma grande expansão, mostrando-se um mercado extremamente competitivo tanto para instituições privadas como para as instituições públicas. Segundo dados do Censo da Educação Superior divulgados pelo Instituto Nacional de Estudos e Pesquisas Educacionais Anísio Teixeira (INEP) do Ministério da Educação (MEC) em 2011, naquele ano existiam no Brasil 2.365 instituições de ensino superior, sendo 103 públicas federais, 110 públicas estaduais, 71 públicas municipais e 2.081 privadas, assim, as instituições públicas representam apenas 12\% desse universo. Em termos de distribuição por região geográfica, praticamente metade das IES $(48,9 \%)$ está localizada na região Sudeste. A outra metade apresenta a seguinte distribuição: $18,3 \%$ no Nordeste, $16,5 \%$ no Sul, $9,9 \%$ no Centro-Oeste e $6,4 \%$ no Norte. (BRASIL, 2013).

Com relação a oferta de cursos, as IES públicas respondem por 32,3\% do total, sendo 9.368 cursos presenciais e 465 à distância, esses cursos resultaram em 1.773.313 matrículas que corresponderam a $26,3 \%$ do total. A Tabela 1 apresenta os dados relacionados as matrículas, ingressos e concluintes dos cursos de graduação no Brasil nos anos de 2008, 2009, 2010 e 2011.

Tabela 1 Número e percentual de matrículas, ingressos e concluintes de graduação (presencial e a distância).

\begin{tabular}{cccccccc}
\hline \multirow{2}{*}{ Ano } & \multirow{2}{*}{ Categoria } & \multicolumn{2}{c}{ Matrículas } & \multicolumn{2}{c}{ Ingressos } & \multicolumn{2}{c}{ Concluintes } \\
\cline { 3 - 7 } & Número & $\%$ & Número & $\%$ & Número & $\%$ \\
\hline \multirow{2}{*}{$\mathbf{2 0 0 8}$} & Total & 5.808 .017 & 100 & 2.336 .899 & 100 & 870.386 & 100 \\
& Pública & 1.552 .953 & 26,7 & 538.474 & 23,0 & 195.933 & 22,5 \\
& Privada & 4.255 .064 & 73,3 & 1.798 .425 & 77,0 & 674.453 & 77,5 \\
\hline \multirow{2}{*}{$\mathbf{2 0 0 9}$} & Total & 5.954 .021 & 100 & 2.065 .082 & 100 & 959.197 & 100 \\
& Pública & 1.523 .864 & 25,6 & 422.320 & 20,5 & 206.877 & 21,6 \\
& Privada & 4.430 .157 & 74,4 & 1.642 .762 & 79,5 & 752.320 & 78,4 \\
\hline \multirow{2}{*}{$\mathbf{2 0 1 0}$} & Total & 6.379 .299 & 100 & 2.182 .229 & 100 & 973.839 & 100 \\
& Pública & 1.643 .298 & 25,8 & 475.884 & 21,8 & 190.597 & 19,6 \\
& Privada & 4.736 .001 & 74,2 & 1.706 .345 & 78,2 & 783.242 & 80,4 \\
\hline \multirow{2}{*}{$\mathbf{2 0 1 1}$} & Total & 6.739 .689 & 100 & 2.346 .695 & 100 & 1.016 .713 & 100 \\
& Pública & 1.773 .315 & 26,3 & 490.680 & 20,9 & 218.365 & 21,5 \\
& Privada & 4.966 .374 & 73,7 & 1.856 .015 & 79,1 & 798.348 & 78,5 \\
\hline
\end{tabular}

Fonte: Censo da Educação Superior - MEC/INEP (BRASIL, 2013).

Observa-se que tanto nas instituições públicas quanto nas privadas os números continuam crescentes, exceto o número de ingressos entre 2008 e 2009, também é perceptível o grande distanciamento entre ingressos e concluintes. Considerando uma média de quatro anos para a conclusão de um curso de graduação - Bacharelado, Licenciatura e Tecnólogo, 
dos 2.336.899 ingressantes em 2008, 1.016.713 concluíram seus cursos no ano de 2011, apenas $43,5 \%$, ou seja, a taxa de evasão correspondeu a 56,5\%. Dado esse panorama, as IES se veem obrigadas a encontrarem soluções, visando a permanência de seus alunos nos cursos escolhidos.

No âmbito das IES Públicas, o Governo Federal através do MEC, têm realizado ações de promoção à permanência e combate à evasão, os alunos destas instituições podem ser beneficiados com o Bolsa-permanência, que é uma ação de auxílio financeiro para estudantes de baixa renda das instituições federais de ensino superior. Esta bolsa é concedida aos estudantes que atendam os critérios para a política de cotas, estejam matriculados em cursos com carga horária maior que cinco horas diárias e que tenham renda per capta familiar mensal de até 1,5 salários mínimos. Seu valor é de $\mathrm{R} \$ 400,00$.

Além disso, o Plano Nacional de Assistência Estudantil (PNAES) apoia a permanência de estudantes de baixa renda matriculados em cursos de graduação presencial das IES Públicas. O PNAES oferece assistência à moradia estudantil, alimentação, transporte, à saúde, inclusão digital, cultura, esporte, creche e apoio pedagógico. As ações são executadas pela própria instituição de ensino, que deve acompanhar e avaliar o desenvolvimento do programa.

\section{PERMANÊNCIA DE ALUNOS NO ENSINO SUPERIOR}

O tema permanência tem sido um assunto bastante abordado por diversos pesquisadores, tanto no contexto nacional como no internacional. O crescimento da oferta no ensino superior observado nas últimas décadas provocou dois resultados que podem ser destacados, o primeiro corresponde ao aparecimento de cursos de baixa qualidade que procuram atrair alunos interessados apenas em diplomas e o segundo, trata-se do acirramento da concorrência entre as instituições de ensino superior. (CISLAGHI, 2008).

Além das dificuldades de enfrentar esse ambiente caracterizado por grande competitividade, as IES sofrem com a questão da evasão de seus alunos, garantir a permanência dos mesmos, tem exigido grande atenção dessas organizações. De acordo com Cislaghi (2008, p. 66) permanência é "o objetivo final de um conjunto de políticas e programas institucionais para manter um estudante e, também, como a resultante de diversos fatores que levam o estudante decidir permanecer num curso".

Neste cenário "o desafio tem sido, para as IES públicas, aplicar bem os recursos públicos assegurando o esperado retorno social, e para as privadas, manter sua clientela formada por estudantes" (CISLAGHI, 2008, p. 1). A evasão em IES públicas representa 
recursos investidos que não proporcionam o retorno desejado, além de provocar ociosidade da estrutura, do corpo docente e técnico administrativo dessas instituições, as estruturas estão lá, esperando os alunos.

Para Cislaghi (2008), dentre as causas possíveis para a ocorrência de evasão em cursos de graduação em IES brasileiras, estudos já realizados apontam a descontinuidade que ocorre entre as sistemáticas no ensino médio e no ensino superior, com este último exigindo mais dos estudantes, a orientação vocacional deficiente para os candidatos ao ingresso nas IES, gerando decepção com o curso ou área escolhido; as dificuldades geradas pela necessidade de estudantes trabalharem para seu sustento financeiro durante o curso, demandando dedicação de tempo e compatibilização dos horários de aulas com a jornada de trabalho; o desapontamento com a qualidade do curso, com os procedimentos didático-pedagógicos, com a qualificação dos docentes e/ou estrutura da instituição; as dificuldades pessoais para um bom desempenho e aproveitamento nas disciplinas resultando em reprovações e ocasionando uma demora excessiva para a integralização curricular; o pessimismo com relação às perspectivas de colocação no mercado de trabalho; a mudança de interesses ou de prioridades pessoais; a necessidade de transferência familiar para outro município ou estado, entre outros.

Para Kotler e Fox (1994), as IES devem manter um programa para a permanência de alunos, os autores indicam que para isso devem ser observadas oito etapas, sendo elas: (1) estabelecer um comitê de direção da permanência, com representação de várias áreas funcionais da instituição, que dará direcionamento ao programa; (2) avaliar a situação da permanência, devendo determinar os registros anteriores de permanência da instituição, analisar números atuais e analisar possíveis fatores de abandono; (3) determinar as causas que estão levando os alunos a abandonar a instituição, através de pesquisa direcionada a alunos já desligados e a alunos matriculados regularmente; (4) encorajar uma atitude de serviço aos alunos, exigindo mudanças, tanto estruturais quanto de serviços, segundo pesquisas; (5) criar condições que atendam objetivos de admissões, impondo condições para que novos alunos requeridos pela instituição evitem que os calouros, não satisfeitos com o curso, deixem a escola; (6) facilitar o trânsito do aluno nas instalações da instituição, mostrando tudo que a mesma oferece ao aluno, incentivando a sua participação; (7) prestar aconselhamento e orientação por profissionais especializados; (8) criar um ambiente de atenção, orientado aos alunos, encorajando o crescimento pessoal, sucesso acadêmico e dando sentimento de posse para o aluno. 
Para Tinto (2003) cinco condições se destacam como suporte à persistência de alunos no ensino superior, são elas: expectativa - elevadas expectativas são uma condição para o sucesso do aluno; aconselhamento - alunos avaliam a coerência das informações do pessoal de aconselhamento; apoio - têm maior chance de permanecer alunos que recebem apoio social e pessoal; participação - a participação e envolvimento com os professores, funcionários e com outros alunos é um importante atributo da permanência, principalmente no primeiro ano de graduação; aprendizagem - os alunos tendem a permanecer nos cursos de graduação que promovam a aprendizagem.

\subsection{ESTUDOS CORRELATOS DOS ANTECEDENTES DE PERMANÊNCIA DE ALUNOS EM IES}

Os primeiros trabalhos sobre a temática da evasão e permanência de alunos em IES foram realizados por pesquisadores estadunidenses, sendo que os estudos de Tinto (1997, 2000, 2003), teórico da educação superior, especialmente na área de permanência de estudantes, são basilares nesta temática. Assim, cabe revisar alguns estudos, tais como Tinto (1997; 2000), Santos (2001), DeShields Jr, Kara e Kaynak (2005), Cislaghi (2008) e Appio (2010).

Tinto (1997) realizou um estudo teve como objetivo identificar o papel das interações em sala de aula na permanência dos alunos na instituição de ensino. A amostra foi composta por 218 estudantes que estavam no seu primeiro ano de seus cursos. Com base em um estudo de caso com método qualitativo, em que os dados levantados foram submetidos à análise quantitativa, o autor concluiu que conhecer pessoas e fazer amigos durante o primeiro ano de faculdade é uma grande preocupação do estudante, especialmente entre mais jovens. $\mathrm{Na}$ análise qualitativa, muitos afirmaram que a universidade é um lugar para conhecer novas pessoas e fazer novos amigos. $\mathrm{O}$ autor sugere que as universidades promovem seminários, projetos em grupo e discussões em classe, isso ajuda a incluir o aluno no grupo e auxilia na aprendizagem. Grupos que se formaram dentro da sala de aula são muitas vezes estendidos para além da sala de aula, o que corresponde a dizer que existem influências de aprendizagem em grupo na permanência do aluno na instituição de ensino. Para o autor, essas relações interpessoais são importantes porque eles formam uma rede de apoio mútuo e de interação social.

Tinto (2000) em outro estudo, realizado em três universidades, sendo duas em Washington e uma em Nova York, evidencia que as universidades estão reestruturando suas 
atividades em sala de aula, com o objetivo de promover aprendizagem compartilhada e colaborativa entre os estudantes. Esta forma de organização exige que os estudantes trabalhem em grupos, tornando-os efetivamente responsáveis pelas atividades, participando do processo de aprendizagem. Ele propõe que, para alcançar este objetivo é necessário que haja um modelo de aprendizagem que incentive a integração entre alunos e professores e promova as redes de relações sociais e acadêmicas entre os estudantes. Esta metodologia de ensino é confirmada pelos resultados do estudo com esses alunos. $\mathrm{O}$ autor conclui que os alunos que participam de redes de relações sociais em sala de aula, tiveram uma taxa substancialmente mais elevada de permanência, em torno de $25 \%$, quando comparados aos alunos que estudaram no estudo tradicional, evidenciando que a participação do acadêmico em sala de aula reforça a aprendizagem e a permanência do aluno no sistema educacional.

Cislaghi (2008) teve como objetivo a construção de um modelo de sistema de gestão do conhecimento, visando a promoção da permanência de estudantes no ensino de graduação em IES brasileiras. O autor realizou um levantamento das causas para a evasão com base num abrangente levantamento de teorias e modelos de desgaste, abandono e permanência, para então, constituir um framework com o objetivo de apoiar uma gestão proativa visando a permanência do aluno.

As causas agrupadas na categoria desempenho acadêmico dizem respeito à variável desempenho em notas, refletindo no progresso acadêmico do aluno. As causas encontradas na categoria ambiente sócio-acadêmico estão associadas aos fatores que influenciam a habilidade do estudante para desenvolver relacionamentos com colegas, outros estudantes, professores e funcionários, dentro e fora dos locais e horários das aulas e demais compromissos acadêmicos rotineiros. As causas para evasão agrupadas na categoria didático-pedagógicas têm relação com a variável integração acadêmica, envolvendo as habilidades inatas ou adquiridas pelos estudantes para exercer seu papel nas relações estudante-professor e estudante-colega, assim como as situações nas quais estas relações ocorrem. Nas questões de interesse pessoal do estudante, o modelo de permanência discente considera as variáveis: compromissos com os objetivos e compromissos com a instituição. As causas para evasão que dizem respeito ao compromisso com o objetivo influenciam a percepção do estudante sobre a qualidade do curso que frequenta e a utilidade que tem para si a formação adquirida e o título pretendido. Estas causas estão agrupadas nas categorias currículo, curso e interesses pessoais. Já o compromisso com a instituição depende da percepção que o estudante tem da IES que frequenta e as causas para evasão que influenciam esta percepção estão agrupadas na 
categoria características institucionais. Cislaghi (2008) considera que a relação entre as causas para a evasão encontradas na categoria condições pessoais têm relações difusas com as variáveis condições financeiras, responsabilidades pessoais e responsabilidades profissionais, sendo estas muito mais voltadas ao ambiente externo à IES e, como tal, menos sujeitas às intervenções institucionais para promover a permanência discente.

DeShields Jr, Kara e Kaynak (2005), pesquisaram os determinantes da satisfação e retenção dos alunos numa universidade que são considerados de impacto na experiência universitária. Com base na teoria dos dois fatores de Herzberg, a pesquisa foi administrada a cerca de 160 estudantes de graduação em negócios de uma universidade estadual em South Central, Pensilvânia. Usando análise do caminho, os efeitos hipotéticos foram testados empiricamente, incorporando um conjunto abrangente de variáveis independentes e avaliações experimentais de auto relato para prever a experiência, relacionado com a satisfação do aluno.

Os resultados indicam que o caminho da faculdade, as aulas, a experiência da faculdade, são fatores-chave que influenciam a experiência do estudante. Além disso, os estudantes que têm uma experiência positiva na faculdade são mais propensos a ficar satisfeitos do que os estudantes que não têm uma experiência positiva. Os autores indicam que, concentrando-se em antecedentes da satisfação dos estudantes, faculdades e universidades podem alinhar a sua estrutura organizacional, processos e procedimentos para tornar-se mais orientada para o cliente.

Santos (2001), por meio de uma pesquisa qualitativa, buscou analisar o perfil dos alunos evadidos da Faculdade de Economia, Administração e Contabilidade da USP Campus de Ribeirão Preto. Os dados foram coletados junto à Pró-Reitoria de Graduação e aos alunos evadidos. Dos 88 alunos evadidos entre 1998 e 2001, foram entrevistados 33. Os resultados indicaram que os fatores que podem influenciar o ato de evadir são: Processo de integração, Vocação, Status Profissional, Ajustamento com o Curso, Oportunidades Profissionais, Estímulos Sociais e Econômicos.

O autor recomenda que as IES criem um Programa de Integração do Calouro; elaboração de um questionário visando avaliar o grau de conhecimento do calouro; levantamento constante das causas de evasão através de formulário a ser preenchido pelo aluno no trancamento de matrícula; atuação efetiva de um professor orientador; e parcerias com empresas da região para a criação de um núcleo de estágios. 
Appio (2010) realizou um estudo sobre os antecedentes da Lealdade e da Permanência de alunos em cursos de graduação. A autora pesquisou 81 alunos do curso de pedagogia, 42 do curso de letras, 212 do curso de engenharia química e 80 alunos do curso de ciências contábeis da Universidade Regional de Blumenau (FURB), onde os alunos, em sua maioria, correspondiam ao gênero feminino, sendo solteiros, com idade média de 21 anos. Em torno de $50,0 \%$ possuíam renda pessoal entre um e três salários mínimos e 24,5\% deles declararam não estar atuando profissionalmente. A pesquisa mostrou que, Satisfação, Reputação/imagem social no mercado e Compromisso emocional com a IES, nesta ordem, foram os principais explicadores diretos da Lealdade e Compromisso do Aluno com suas Metas Pessoais, Satisfação com a IES e Situação Financeira Favorável, foram os principais explicadores diretos da Permanência.

\section{PROCEDIMENTOS METODOLÓGICOS}

Quanto a abordagem, essa pesquisa classifica-se como quantitativa, de caráter descritivo. Os estudos de caráter descritivo, segundo Vergara (2003, p. 47), “expõe características de determinada população ou de determinado fenômeno. Pode também estabelecer correlações entre variáveis e definir sua natureza. Não tem compromisso de explicar os fenômenos que descreve, embora sirva de base para tal explicação". Richardson (1999) justifica a aplicação do uso do método de pesquisa quantitativa em estudos descritivos nas ciências sociais, pois permite controlar grande número de variáveis e, por meio de técnicas estatísticas, especificar o grau pelo qual as variáveis estão relacionadas.

Dessa forma, a pesquisa quantitativa teve como objetivo indicar as percepções dos alunos de alunos sobre a permanência na instituição que estudam. Para tanto, a técnica de amostragem aplicada nesta pesquisa é classificada como probabilística, sendo que a população foi de 524 alunos matriculados regularmente nos cursos de graduação no primeiro semestre de 2014. Destes, procedeu-se o cálculo de amostragem admitindo erro amostral de $5 \%$ tendo-se como amostragem 228 alunos.

O instrumento aplicado nessa pesquisa foi um questionário fechado que teve como base o modelo proposto por Appio (2010). O questionário, por ser adaptado à esta pesquisa, foi testado com objetivo de identificar possíveis erros de formulação e interpretação. Em seguida, procedeu-se a aplicação do questionário por acessibilidade e/ou conveniência, sendo que o pesquisador aplicou a pesquisa nas salas durante o período de aula. Os dados foram coletados na primeira quinzena do mês de agosto de 2014, que correspondeu ao final do 
primeiro semestre na instituição. Com a utilização de questionário fechado, a análise dos dados foi realizada estatisticamente através dos softwares Statistical Package for the Social Science (SPSS) versão 15 e Excel. As análises realizadas foram: Análise descritiva; Análise Kaiser-Meyer-Olkin (KMO) e Bartlett's test (esferidade de Bartlett); Análise fatorial; Análise de regressão.

Das variáveis que fizeram parte do instrumento de coleta de dados, o construto tendência de permanência foi considerado como dependente e os demais construtos e suas variáveis foram considerados independentes para fins de análise de regressão.

\section{ANÁLISE DOS RESULTADOS}

\subsection{PERFIL DA AMOSTRA}

Quanto ao perfil, dos 228 alunos, 17,10\% pertenciam ao curso de Tecnologia em Alimentos, 27,20\% eram do curso de Licenciatura em Informática, 41,67\% do curso de Engenharia Ambiental e 14,03\% cursavam Engenharia Química. A análise da faixa etária dos estudantes apresentou uma média de 22 anos com desvio padrão de 4,68 anos. O mais jovem declarou ter 16 anos e o mais idoso 50 anos. O curso de Engenharia Química apresentou a maior concentração de alunos na faixa de 17 e 23 anos (93,75\%), seguido do curso de Engenharia Ambiental (93,62\%), os cursos de Licenciatura em Informática e Tecnologia em Alimentos apresentaram uma distribuição mais heterogenia.

Quanto ao gênero, dos 228 alunos pesquisados, 227 declararam gênero, sendo que a maioria, 124 (54,62\%) eram do sexo Feminino e 103 (45,38\%) eram do sexo Masculino, a distribuição apresentou ainda importantes variações entre os cursos pesquisados, onde no curso de Licenciatura em Informática a maioria, 72,58\%, eram do sexo masculino e nos de Tecnologia em alimentos, Engenharia Ambiental e Engenharia Química a proporção se inverteu, apresentando valores acima de $60 \%$ para o sexo feminino. Na análise do estado civil a grande maioria eram solteiros $(83,33 \%)$, com destaque para o curso de Engenharia Química onde todos se declararam solteiros.

Analisou-se também a atuação profissional do aluno os dados da pesquisa apresentaram que 147 (64,76\%) não trabalhavam, 14 (6,17\%) trabalhavam em meio período e $66(29,07 \%)$ trabalhavam em período integral, dos 80 que declararam estar trabalhando, 39 atuavam na área do curso, nas engenharias (Ambiental e Química) a grande maioria (96,85\%) dos respondentes não trabalha, em contraste, nos cursos do período noturno (Licenciatura em 
Informática e Tecnologia em Alimentos) 76\% trabalham em meio período ou período integral. Essas diferenças podem ser explicadas pelo perfil dos próprios cursos pesquisados.

\subsection{ESTATÍSTICA DESCRITIVA DAS VARIÁVEIS DA PESQUISA}

Das variáveis pesquisadas dez delas apresentaram médias acima de 6 pontos na escala Likert, com destaque para a variável, Q42 (Ter curso superior hoje é fundamental para o mercado de trabalho) com um escore próximo ao limite superior da escala $(6,65)$ e também para as variáveis, Q12 (Tenho orgulho em poder estudar na ...), Q13 (Tenho orgulho em pertencer à ...) e Q14 (Tenho orgulho do curso que escolhi), com escores de 6,29, 6,25 e 6,08 respectivamente, sendo que essas variáveis se agrupam no construto Compromisso emocional com a instituição.

Entre as variáveis com as menores médias, quatorze apresentaram escores abaixo de 5 pontos, onde a variável Q31 (Minha situação financeira tem causado preocupação, stress e ansiedade), apresentou uma média de 4,06 sendo o menor valor observado. Com relação aos agrupamentos, cabe destaque as variáveis, Q32 (O curso que eu faço é melhor do que eu esperava) com média de 4,81, Q33 (A ... superou minhas expectativas) com média de 4,89 e Q34 (A qualidade das aulas e professores superou minhas expectativas) com média de 4,77, que se agrupam no construto Atendimento às expectativas, e também as variáveis, Q35 (Consigo compatibilizar minha vida pessoal ou profissional com o curso que faço) com média de 4,93, Q36 (Tenho tempo disponível para estudar) com média de 4,63 e Q37 (Consigo conciliar e dispor de tempo e de estrutura para atender às exigências do curso) com média de 4,48, que formam o construto Vida pessoal.

Um desvio padrão de 0 significaria que escores são os mesmos, a análise indica que houveram flutuações, onde sete variáveis apresentaram valores abaixo de 1 variando entre 0,77 e 0,99, com destaque para as variáveis Q42 (Ter curso superior hoje é fundamental para o mercado de trabalho) e Q66 (O curso que faço na ... possibilita aprendizado), com escores abaixo de 0,90, podendo-se destacar novamente o construto Compromisso emocional com a instituição, com duas de suas três variáveis, Q12 (Tenho orgulho em poder estudar na ...) e Q13 (Tenho orgulho em pertencer à ...).

Quanto as variáveis com os maiores valores de desvio padrão, pode-se destacar as variáveis Q30 (Preciso do auxílio de bolsas ou de terceiros - empresa, etc. - para concluir o curso) e Q31 (Minha situação financeira tem causado preocupação, stress e ansiedade), que fazem parte do construto Situação financeira do aluno, que tiveram desvio padrão 
relativamente alto comparado à média, com 2,11 e 2,09 respectivamente, mas em geral não ocorreram grandes variações, tendo a média uma boa aderência aos dados.

\subsection{ANÁLISE DE ASSIMETRIA E CURTOSE, DIMENSIONALIDADE E CONFIABILIDADE DOS CONSTRUTOS}

Nesta fase procedeu-se a análise de frequência e dispersão dos dados coletadas na pesquisa. A assimetria verifica a distribuição da amostra, quanto mais distribuídas forem as respostas, e ou quanto mais as mesmas se posicionam ao longo de uma extremidade ou de outra mais assimétrica elas são. Quanto se tem valores de assimetria maiores do que +1 ou menores do que -1 , indica tratar-se de uma distribuição substancialmente assimétrica. (HAIR JR. et al., 2005). Já a curtose é uma medida do pico ou achatamento de uma distribuição. Quando as respostas de uma escala se aglomeram no centro são tidas como agudas. As distribuições com escores mais amplamente distribuídas e extremidades mais separadas são consideradas achatadas. Diz-se que uma curva é muito aguda quando excede +3 e é muito achatada quando ela fica abaixo de -3. (HAIR JR. et al., 2005).

Após a análise de assimetria e curtose, procedeu-se a análise de correlação para identificar possíveis problemas de multicolineariedade nos dados, e este erro não foi identificado. Assim, as variáveis que se enquadravam dentro dos limites aceitos pela literatura foram submetidas aos testes de Kaiser-Meyer-Olkin (KMO) e Bartlett's test (esferidade de Bartlett), apresentando para KMO o valor de: 0,788 tido como um bom resultado, pois, valores entre 0,5 e 0,7 são medíocres, valores entre 0,7 e 0,8 são bons e valores entre 0,8 e 0,9 são muito bons. (FIELD, 2009). E o teste de esferidade de Bartlett apresentou-se menor que 0,000 confirmando que método de análise fatorial para o tratamento dos dados era possível e adequado.

Após verificado o nível de confiança, foi realizada a análise fatorial ou análise de fatores (Tabela 2), buscando validar os construtos da pesquisa, ou seja, "analisar a estrutura das inter-relações (correlações) entre um grande número de variáveis [...] definindo um conjunto de dimensões latentes comuns, chamada de fatores”. (HAIR JR. et al., 2005, p. 91). Além disso, a análise fatorial possibilita identificar variáveis não correlacionadas ou que representam mais que um conceito, determinando quais entre elas deverão ser excluídas da análise. Na rotação pelo método Varimax, as variáveis com cargas fatoriais menores que 0,4 ou que não possuíam correlação com seu fator foram eliminadas. (HAIR JR. et al., 2005). 
Tabela 2 Análise fatorial dos componentes principais.

\begin{tabular}{|c|c|c|c|c|c|c|c|c|c|}
\hline \multirow[b]{2}{*}{ Construtos } & \multirow[b]{2}{*}{ Variáveis } & \multicolumn{8}{|c|}{ Componentes } \\
\hline & & $\begin{array}{c}\text { Fator } \\
1\end{array}$ & $\begin{array}{c}\text { Fator } \\
2\end{array}$ & $\begin{array}{c}\text { Fator } \\
3\end{array}$ & $\begin{array}{c}\text { Fator } \\
4\end{array}$ & $\begin{array}{c}\text { Fator } \\
5\end{array}$ & $\begin{array}{c}\text { Fator } \\
6\end{array}$ & $\begin{array}{c}\text { Fator } \\
7\end{array}$ & $\begin{array}{c}\text { Fator } \\
8\end{array}$ \\
\hline \multirow{3}{*}{ Atendimento às expectativas } & Q33 & ,835 & & & & & & & \\
\hline & Q32 & ,806 & & & & & & & \\
\hline & Q34 & ,770 & & & & & & & \\
\hline \multirow{3}{*}{ Desempenho acadêmico } & Q25 & & ,807 & & & & & & \\
\hline & Q22 & & ,764 & & & & & & \\
\hline & Q23 & & ,710 & & & & & & \\
\hline \multirow{3}{*}{$\begin{array}{l}\text { Confiança do aluno na } \\
\text { Instituição }\end{array}$} & Q26 & & & ,912 & & & & & \\
\hline & Q27 & & & ,845 & & & & & \\
\hline & Q28 & & & ,686 & & & & & \\
\hline \multirow{2}{*}{ Infraestrutura do Campus** } & Q56 & & & & ,715 & & & & \\
\hline & Q64 & & & & ,659 & & & & \\
\hline \multirow{3}{*}{$\begin{array}{l}\text { Atividades de estágio ou ex- } \\
\text { tracurriculares }\end{array}$} & Q52 & & & & & ,839 & & & \\
\hline & Q51 & & & & & 827 & & & \\
\hline & Q53 & & & & & ,805 & & & \\
\hline \multirow{3}{*}{ Vida pessoal } & Q36 & & & & & & 887 & & \\
\hline & Q37 & & & & & & ,874 & & \\
\hline & Q35 & & & & & & ,659 & & \\
\hline \multirow{3}{*}{ Situação financeira do aluno } & Q30 & & & & & & & ,844 & \\
\hline & Q31 & & & & & & & 817 & \\
\hline & Q29 & & & & & & &,- 751 & \\
\hline \multirow{2}{*}{ Imagem social da IES } & Q16 & & & & & & & & ,842 \\
\hline & Q15 & & & & & & & & ,775 \\
\hline
\end{tabular}

Fonte: Da pesquisa, 2014.

*Nota: Método de extração: Análise dos Componentes Principais. Método de Rotação: Varimax with Kaiser Normalization.

Após a rotação, as variáveis Q5 (Participo em atividades extraclasse com minha turma de sala de aula), Q20 (Existe possibilidade de boa colocação dos alunos da ... no mercado de trabalho), Q43 (Sempre alcanço meus objetivos pessoais), Q46 (O curso dá retorno das reclamações e sugestões aos alunos) e Q49 (Os professores têm disposição para preparar e conduzir as aulas) foram excluídas e os construtos infraestrutura do Campus e Acesso à infraestrutura foram agrupados, resultando em 8 fatores ou 8 construtos, são eles:

Fator 1 ou Construto 1 - Atendimento às expectativas: A .... superou minhas expectativas (Q33), O curso que eu faço é melhor do que eu esperava (Q32), A qualidade das aulas e professores superou minhas expectativas (Q34);

Fator 2 ou Construto 2 - Desempenho acadêmico: Estou satisfeito(a) com meu desempenho em trabalhos e estudos extraclasse (Q25), Estou satisfeito(a) com meu desempenho em notas (Q22), Estou conseguindo acompanhar os conteúdos do curso (Q23); 
Fator 3 ou Construto 3 - Confiança do aluno na Instituição: As pessoas que trabalham na ... são honestas (Q26), As pessoas que trabalham na ... são integras (Q27), As pessoas que trabalham na ... cumprem com o que prometem $(\mathrm{Q} 28)$;

Fator 4 ou Construto 4 - Infraestrutura do Campus: A infraestrutura existente no campus é adequada às necessidades dos alunos (Q56), Os serviços de apoio em geral são de fácil utilização e acesso (Q64);

Fator 5 ou Construto 5 - Atividades de estágio ou extracurriculares: São realizadas atividades práticas durante o curso (Q52), A ... apoia a realização de estágios, visitas e/ou viagens de estudo (Q51), As atividades de estágio, visitas e/ou viagens de estudo têm contribuído para o meu aprendizado no curso (Q53);

Fator 6 ou Construto 6 - Vida pessoal: Tenho tempo disponível para estudar (Q36), Consigo conciliar e dispor de tempo e de estrutura para atender às exigências do curso (Q37), Consigo compatibilizar minha vida pessoal ou profissional com o curso que faço (Q35);

Fator 7 ou Construto 7 - Situação financeira do aluno: Preciso do auxílio de bolsas ou de terceiros (empresa, etc.) para concluir o curso (Q30), Minha situação financeira tem causado preocupação, stress e ansiedade (Q31), Minha renda pessoal ou familiar é suficiente para arcar com os custos do curso (Q29);

Fator 8 ou Construto 8 - Imagem social da IES: A sociedade reconhece as ações executadas pela ... (Q16), A ... pratica ações que contribuem com a sociedade (Q15).

\subsection{ANÁLISE DE REGRESSÃO DO MODELO}

O quadro a seguir apresenta o resultado do teste de regressão. Para a análise de regressão, as dimensões: Atendimento as expectativas; Desempenho acadêmico; Confiança do aluno na instituição; Acesso a infraestrutura do campus e do curso; Atividade de estágio ou extracurricular; Vida pessoal; Situação financeira do aluno e Imagem Social foram consideradas construtos preditoras (variáveis independentes), já a tendência a permanência foi considerada como construto dependente.

\begin{tabular}{|c|c|c|c|c|}
\hline Modelo & $\mathrm{R}$ & $\mathrm{R}^{2}$ & $\mathrm{R}^{2}$ ajustado & Erro estimado \\
\hline 1 &, $380(\mathrm{a})$ &, 144 &, 113 & 1,29375 \\
\hline
\end{tabular}

Quadro 1 Análise de regressão dos construtos de pesquisa. Fonte: Da pesquisa, 2014. 
A análise de regressão apresentou um $\mathrm{R}^{2}=0,113$ (significância de 0,$000 ; \mathrm{F}: 4,622$ ). Sendo assim, os dados indicam que $11,3 \%$ da variabilidade total da tendência a permanência pode ser explicada pelos construtos independentes consideradas significativas.

Para verificar a validade global do modelo também foi realizada uma análise de variância (HAIR JR et al., 2005). O resultado da análise de variância (ANOVA) aparece na Tabela 3, o resultado da ANOVA foi significativo $(0,000)$, o que permite inferir que há evidências de que o modelo pode se adequar ao estudo proposto.

Tabela 3 Análise de variância do modelo de regressão.

\begin{tabular}{ccccccc}
\hline \multirow{2}{*}{ Modelo } & & $\begin{array}{c}\text { Soma dos } \\
\text { quadrados }\end{array}$ & $\begin{array}{c}\text { Graus de } \\
\text { liberdade }\end{array}$ & Quadrado médio & F & Significância \\
\hline \multirow{2}{*}{1} & Regressão & 61,892 & 8 & 7,736 & 4,622 & \multirow{2}{*}{$000(\mathrm{a})$} \\
& Resíduos & 366,559 & 219 & 1,674 & & \\
\hline
\end{tabular}

Fonte: Da pesquisa, 2014.

Quando realizada a análise de regressão nos construtos: Atendimento as expectativas; Desempenho acadêmico; Confiança do aluno na instituição; Acesso a infraestrutura do campus e do curso; Atividade de estágio ou extracurricular; Vida pessoal; Situação financeira do aluno e Imagem Social, consideradas como construtos preditores (independentes), não foram significativas. Apenas os construtos: Atendimento as expectativas, com coeficiente 0,212 e significância de $p<0,05$; Confiança do aluno na instituição, coeficiente 0,227 e significância de $p=0,00$; Situação financeira do aluno, coeficiente de 0,196 e significância $p<0,05$ explicam o construto dependente tendência a permanência, conforme apresentado na Tabela 4.

Tabela 4 Resultado da análise de regressão.

\begin{tabular}{|c|c|c|c|c|c|c|}
\hline \multirow[t]{2}{*}{ Modelo } & \multirow[t]{2}{*}{ Construtos } & \multicolumn{2}{|c|}{$\begin{array}{l}\text { Coeficiente não } \\
\text { padronizado }\end{array}$} & \multirow{2}{*}{$\begin{array}{c}\begin{array}{c}\text { Coeficientes } \\
\text { padronizados }\end{array} \\
\text { Beta } \\
\end{array}$} & \multirow{2}{*}{$\frac{\mathrm{t}}{\mathrm{B}}$} & \multirow{2}{*}{$\begin{array}{c}\text { Sig. } \\
\text { Sig }(p)\end{array}$} \\
\hline & & $\mathrm{B}$ & Erro & & & \\
\hline \multirow[t]{9}{*}{1} & (Constant) & 6,059 & ,086 & & 70,719 &, 000 \\
\hline & Atendimento as expectativas & ,292 & ,086 & ,212 & 3,397 &, 001 \\
\hline & Desempenho acadêmico & ,019 & ,086 &, 014 &, 224 &, 823 \\
\hline & $\begin{array}{l}\text { Confiança do aluno na } \\
\text { instituição }\end{array}$ & ,311 & ,086 & ,227 & 3,626 &, 000 \\
\hline & $\begin{array}{l}\text { Acesso a infraestrutura do } \\
\text { campus e do curso }\end{array}$ & ,033 & ,086 &, 024 & ,383 & ,702 \\
\hline & $\begin{array}{l}\text { Atividade de estágio ou } \\
\text { extracurricular }\end{array}$ & ,099 & ,086 & 072 & 1,151 & ,251 \\
\hline & Vida pessoal &, 034 & ,086 &, 025 & ,400 &, 690 \\
\hline & Situação financeira do aluno &, 269 & ,086 & , 196 & 3,135 &, 002 \\
\hline & Imagem Social &, 076 & ,086 & 055 & ,886 & ,377 \\
\hline
\end{tabular}

Fonte: Da pesquisa, 2014.

* Nota: construto dependente: Tendência a permanência 
Com base no modelo testado os três construtos: Atendimento as expectativas; Confiança do aluno na instituição e Situação financeira do aluno explicam 11,3\% da variabilidade total da tendência a permanência. Primeiramente, abordou-se os construtos que se apresentaram como explicadores da permanência, relacionando os resultados aqui verificados com os encontrados por outros autores que também realizaram pesquisas sobre a temática. O construto com maior influência direta sobre a permanência foi o Confiança do aluno na instituição, com significância de $p<0,05$. Esta associação, não havia sido contemplada na literatura revisitada neste estudo, estando mais voltada para questões de lealdade, conforme aponta Appio (2010).

Assim como nos resultados encontrados por Appio (2010), Cislaghi (2008) e Santos (2001) a pesquisa apresentou relação direta entre a situação financeira do aluno e a tendência a permanência no curso, já que o construto Situação financeira do aluno teve uma significância $p<0,05$.

Atendimento as expectativas também se apresentou influenciadora direta na permanência do aluno, com significância de $p<0,05$, confirmando a associação encontrada por Tinto (2003) e Santos (2001) entre esses dois construtos, vale lembrar que esse resultado não corrobora com o encontrado por Appio (2010). Uma possível resposta seja influenciada por variáveis de contingencia não abordadas no estudo de Appio (2010) e neste estudo. Desta forma, novas pesquisas podem ser aplicadas para verificar a relação entre este construto e a permanência. Já o construto Desempenho acadêmico, com significância de $(p=0,823)$ não mostrou possuir relação direta com a permanência, portanto, não corroborou a afirmação de Cislaghi (2008) de que os resultados acadêmicos formais, objetivados no desempenho em notas, são um importante preditor da permanência de alunos no ensino superior, porém foi de encontro com os resultados encontrados por Appio (2010).

Acesso a infraestrutura do campus e do curso não se mostrou relacionada diretamente a tendência a permanência, o construto apresentou significância de $(p=0,702)$, de certa forma corroborando os resultados encontrados por Appio (2010) que indicaram apenas relação indireta entre os construtos. Atividade de estágio ou extracurricular com significância de $p>0,05$ (0,251), não se apresentou relação direta significativa com a tendência a permanência, assim como não está indicado como tal na literatura pesquisada. Com significância de $p>0,05$ $(0,690)$ o construto Vida pessoal não apresentou relação direta com a permanência, esse resultado corrobora com o encontrado por Appio (2010) em sua pesquisa. Por fim, Imagem 
Social apresentou significância de $p>0,05$ (0,377), indicando que não existe relação direta significativa deste construto com a tendência a permanência.

\section{CONCLUSÃO}

O objetivo principal deste trabalho foi identificar os atributos de permanência de alunos em uma instituição pública de ensino superior, para alcançar este objetivo foram definidas algumas etapas, apresentadas como objetivos específicos desta pesquisa, são eles:

- Caracterizar os alunos pesquisados;

- Descrever os atributos de permanência destes alunos;

- Identificar quais atributos influenciam na permanência de alunos no ensino superior.

Assim, discute-se a seguir cada um dos objetivos específicos.

O objetivo específico caracterizar os alunos pesquisados foi atingido com a apresentação do perfil da amostra. Neste contexto, participaram da pesquisa 39 alunos do curso de Tecnologia de Alimentos, 62 alunos do curso de Licenciatura em Informática, 95 do curso de Engenharia Ambiental e 32 alunos do curso de Engenharia Química. A maioria eram solteiros, $54,62 \%$ correspondiam ao gênero feminino, com idade média de 22 anos, $65 \%$ não trabalhavam, 50\% não contavam com qualquer tipo de renda pessoal e a maioria tinha renda familiar de 1 a 3 salários mínimos.

O segundo objetivo específico, descrever os atributos de permanência dos alunos pesquisados foi alcançado com a apresentação das estatísticas descritivas das variáveis de pesquisa, através da média e do desvio padrão, estas apresentaram em sua maioria (65\%) médias acima de 5 pontos, sendo que dez variáveis apresentaram médias acima de 6 pontos, com destaque para a variável, Q42. Ter curso superior hoje é fundamental para o mercado de trabalho, com um escore de 6,65 muito próximo ao limite superior da escala e também para o construto compromisso emocional com a instituição, que apresentou uma média de 6,21. Das variáveis com as menores médias observadas, quatorze apresentaram escores abaixo de 5 pontos, onde a variável Q31. Minha situação financeira tem causado preocupação, stress e ansiedade, apresentou o menor valor observado, uma média de 4,06. Para o desvio padrão, foram observadas flutuações, porém no geral não ocorreram grandes variações, tendo a média uma boa aderência aos dados.

Por fim, o objetivo específico, identificar quais atributos influenciam na permanência de alunos no ensino superior foi satisfeito com a apresentação dos resultados da análise de regressão dos construtos da pesquisa. Com base no modelo testado os três construtos: 
Atendimento as expectativas; Confiança do aluno na instituição e Situação financeira do aluno explicam $11,3 \%$ da variabilidade total da tendência a permanência.

O construto com maior influência direta sobre a permanência foi o Confiança do aluno na instituição, com significância de $p<0,05$ e Beta de 0,227. Esta associação, não havia sido contemplada na literatura pesquisada, estando mais voltada para questões de lealdade. $\mathrm{O}$ construto Atendimento às expectativas também apresentou-se como uma influência direta na permanência do aluno, com significância de $p<0,05$ e Beta 0,212. Situação financeira do aluno teve uma significância $p<0,05$ e Beta de 0,196.

Uma das limitações da pesquisa deu-se por algo inerente à abordagem quantitativa, como por exemplo, sua dificuldade em estabelecer relação de causa-efeito e não conseguir captar o ponto de vista do indivíduo, que resulta na incapacidade de explicar completamente o fenômeno observado. Outra limitação encontrada foi a dificuldade na aplicação dos questionários de pesquisa, pois o período de aplicação coincidiu com o final de semestre na instituição.

Quanto as sugestões para pesquisas futuras, sugere-se a realização de pesquisa sobre a problemática em outras instituições da cidade e também da região a fim de verificar se os resultados estão relacionados de forma preponderante à instituição ou a questões externas. Também deveria ser investigada a modalidade de Educação a Distância, devido ao seu grande crescimento nos últimos anos ao passo que a grande maioria das pesquisas já realizadas versarem sobre a modalidade presencial.

\section{REFERÊNCIAS}

APPIO, J. Antecedentes da lealdade e da permanência de alunos em uma instituição de ensino superior. 2010. 169f. Dissertação (Mestrado em Administração) - Centro de Ciências Sociais Aplicadas, Universidade Regional de Blumenau, Blumenau, 2010. Disponível em: <proxy.furb.br/tede/tde_busca/arquivo.php?codArquivo=729>Acesso em:02 de Abr. de 2014.

BRASIL.Congresso Nacional. Plano Nacional da Educação. 2000. Disponível em: $<$ http://portal.mec.gov.br/arquivos/pdf/pne.pdf>. Acesso em: 17 de Abril de 2014.

BRASIL. Ministério da Educação. Censo da Educação Superior 2011: Resumo Técnico. 2013. Disponível em:

$<$ http://download.inep.gov.br/educacao_superior/censo_superior/resumo_tecnico/resumo_tec nico_censo_educacao_superior_2011.pdf $>$. Acesso em: 17 de Abril de 2014.

BRASIL. Ministério da Educação. Reuni 2008: Relatório, 2009 - Disponível em: $<$ http://portal.mec.gov.br/index.php?option=com_docman\&task=doc_download\&gid=2069\& Itemid=> Acesso em: 08 de Abril de 2014. 
CISLAGHI, Renato. Um modelo de sistema de gestão do conhecimento em um framework para a promoção da permanência discente no ensino de graduação. 2008. 253f. Tese (doutorado) Universidade Federal de Santa Catarina, Centro Tecnológico. Programa de Pós-graduação em Engenharia e Gestão do Conhecimento. 2008. Disponível em: $<$ http://btd.egc.ufsc.br/wp-content/uploads/2010/06/Renato-Cislaghi.pdf $>$. Acesso em: 16 de Maio de 2014.

CORRÊA, Henrique L.; CAON, Mauro. Gestão de serviços: lucratividade por meio de operações e de satisfação dos clientes. 1. ed. São Paulo: Atlas, 2006.

DESHIELDS JR, Oscar W; KARA, Ali; KAYNAK, Erdener. Determinants of business student satisfaction and retention in higher education: applying Herzbergees two-factor theory. International Journal of Educational Management, v. 19, n. 2, p. 128-139, 2005.

FIELD, A. Descobrindo a estatística usando SPSS. 2. ed. Porto Alegre: Artmed, 2009.

FITZSIMMONS, James A.; FITZSIMMONS, Mona J. Administração de serviços: operações, estratégia e tecnologia da informação. 4. ed. Porto Alegre: Bookman, 2005.

HAIR JR., J. F.; ANDERSON, R; E.; TATHAM, R. L.; BLACK, W. C. Análise multivariada de dados. 5. ed. Porto Alegre: Bookman, 2005.

KOTLER, Philip; FOX, Karen F. A.. Marketing estratégico para instituições educacionais. São Paulo, SP: Atlas, 1994.

RICHARDSON, Roberto J. Pesquisa Social: Métodos e técnicas. São Paulo: Atlas, 1999.

SANTOS, F. F. F. Estudo do Perfil dos Alunos Evadidos da Faculdade de Economia, Administração e Contabilidade - Campus Ribeirão Preto. In: Encontro da ANPAD, 2001, Campinas /SP. Anais... Rio de Janeiro. EnANPAD, 2001. Disponível em:

http://www.anpad.org.br/evento.php?acao $=$ trabalho\&cod_edicao_subsecao $=50 \&$ cod_evento edicao=5\&cod_edicao_trabalho=2902\#self. Acesso em: 03 de Maio de 2014.

TINTO, Vicente. Classrooms as Communities: Exploring the Educational Character of Student Persistence. Journal of Higher Education, Vol. 68, No. 6, November/December, 1997.

Enhancing Student Persistence: Connecting the Dots. The challenge of access and Persistence. Wisconsin Center for the Advancement of Postsecondary Education. May 2003.

Learning better together: The impact of learning communities on student success in higher education. Journal of Institutional Research, 9 (1), 48-53, 2000.

VERGARA, Sylvia C. Projetos e relatórios de pesquisa em administração. São Paulo: Atlas, 2003. 
TINTO, Vicente. Classrooms as Communities: Exploring the Educational Character of Student Persistence. Journal of Higher Education, Vol. 68, No. 6, November/December, 1997.

. Enhancing Student Persistence: Connecting the Dots. The challenge of access and Persistence. Wisconsin Center for the Advancement of Postsecondary Education. May 2003.

Learning better together: The impact of learning communities on student success in higher education. Journal of Institutional Research, 9 (1), 48-53, 2000. 